\title{
THE NATURAL FORMATION AND OCCURRENCE OF GREEN QUARTZ
}

\author{
By Thomas R. Paradise
}

Amethyst may develop into the more common citrine and rarer green quartz naturally under certain geologic conditions. On the California-Nevada border, just north of Reno, amethyst, citrine, and green quartz do occur together in clusters of crystals in detritus. These crystals, found lying loose in rocky and sandy rubble, appear to have eroded from cavities and vesicles in the inaccessible cliffs above. The quartz was deposited in these spaces by the slow accumulation of silica from migrating solutions. Low-grade radiation over a geologic time span was responsible for the alteration of the ferric and ferrous quartz into its amethystine color. Secondary, high-temperature, extruding volcanic bodies are believed to be responsible for the subsequent color change to citrine or green quartz.

It has been known for some time that amethyst from specific locations may turn green rather than the expected, and more common, citrine-yellow when subjected to controlled induced heating. For the most part, gem-quality green quartz (also known in the industry as prasiolite or "greened amethyst" $\mid$ is produced by exposing amethyst to high temperatures for a specific period of time. Amethyst from the Montezuma area of Brazil is noted for its purple color alteration to green when subjected to these temperature conditions (Webster, 1978). According to Nassau (1980), exposure of amethyst to temperatures ranging from $140^{\circ} \mathrm{C}$ to $380^{\circ} \mathrm{C}$ for one hour is sufficient to artificially alter the purple to green or yellow. Although this induced heating develops the unusual green color in Brazilian amethyst, in very rare cases nature has supplied the required impurities, radiation, and high temperatures to create green quartz without man's aid.

In 1979, the author and two colleagues examined one such occurrence on the Nevada-California border, where ideal conditions have produced amethyst, citrine, and green quartz (see figure 1) in close proximity. An area of approximately $3 \mathrm{~km}^{2}$ was studied, with uncovered crystals ranging in size from 3 to $55 \mathrm{~mm}$ in length. Iron impurities in the silicon dioxide in conjunction with

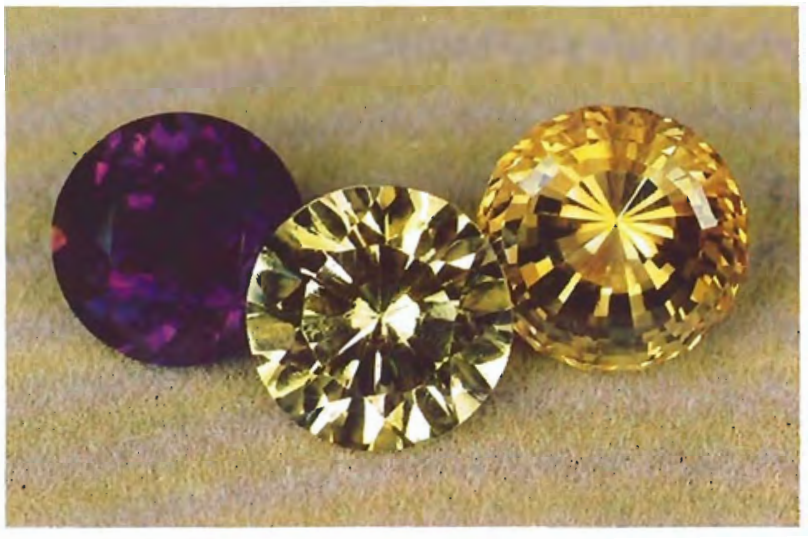

Figure 1. Amethyst (3.77 cts.), green quartz (4.99 cts.), and citrine (5.74 cts.) faceted from rough material found at the same location along the California-Nevada border.

Photograph by Tino Hammid, GIA Gem Media.

an optimal radiation dosage were required to produce amethystine purple. Through subsequent heating and the resulting disruption of the purple color center, the characteristic yellow of citrine and the less common green quart $z$ were produced.

\section{GEOLOGY OF THE AREA}

The quartzes were discovered in pebbly talus below steep basalt-andesite cliffs, approximately one-half kilometer to the east of Interstate Highway $395,33 \mathrm{~km}$ (19 miles) north of Reno, Nevada. The amethyst, citrine, and green quartz specimens were found by the author in a detrital area that followed the base of the cliffs for approximately $3 \mathrm{~km}$ and no farther from the cliff face than the highway. The quartz appeared as crystal

\footnotetext{
ABOUT THE AUTHOR

Mr. Paradise is a geological consultant, gemologist, and registered jeweler with Gleim Jewelers, Palo Alto, CA.

Acknowledgments: The author gives special thanks to Laurel Thompson for her great professional advice, to Donald Laufer for his fine work on faceting the gems illustrated in this article, and to Mr. Arthur Gleim for his encouragement and example.

1982 Gemological Institute of America
} 
clusters, single crystals, and portions of crystals, with no quartz found in situ. Exploration of the area indicated that the quartz had formed in the inaccessible basalt-andesite cliffs. A large talus slope and alluvial fans extend from the base of the cliff to the roadway; here, within a few hundred meters of the cliff base, the detrital crystals were unearthed. The host rock material, which consisted primarily of basalt with andesite, is actually metavolcanic. The prefix meta denotes a material that has been changed by subsequent events; in this case, the extruded material was later altered by further heating. This basalt-andesite mass is filled with lenses of brecciated and pyroclastic material, as well as with the numerous vesicles and amygdules that are ideal for the secondary silica deposition required for the formation of quartz (Stinson, 1960). The origin of the host basalt-andesite dates back approximately 140 million years (Jurassic period), coinciding with the early formation of the Sierran mountain core (Hill, 1975).

The quartz was deposited after the cooling and microcrystallization of the basalt-andesite. During the solidification of the lava (the basalt-andesite in its fluid state), trapped gases slowly accumulated and ascended, producing the vesicles, bubbles, and vug areas that are easily observed from the cliff base. As aqueous solutions migrated through the porous basaltic rock, they became enriched with soluble elements such as silica, which is soluble at very high temperatures or in an alkaline environment, that were slowly deposited from the saturated fluids onto the cavity walls (Sinkankas, 1959). Chalcedony, the cryptocrystalline variety of quartz, was deposited initially. As the siliceous solutions became less saturated, slower, more controlled crystallization occurred. The larger crystals developed very gradually from the ferrous and ferric siliceous solutions deposited on the chalcedony, with subsequent lengthy low-grade radiation exposure providing the energy required for the formation of the amethyst color center (Nassau, 1980). Lowgrade radiation is a common natural occurrence during times of volcanic activity.

After the formation of the crystalline quartz and its alteration to amethyst, the area underwent a period of major metamorphism. Approximately 30 million years ago (Oligocene epoch), the basalt-andesite was overlaid and bordered by a major volcanic extrusion of rhyolite (Bateman,
1960), which appears to have produced temperatures of sufficient degree and duration to force the radiation-induced amethyst color center into an unstable state, whereby the color was altered from amethystine purple to either the brownish yellow typical of citrine or the far less common green.

The hot extrusion caused the underlying basalt material to alter in the areas closest to the rhyolite. The degree of such metamorphism is relative to the degree of heat, so that the higher the temperature is, the greater the bleaching of the amethyst should be. If this theory is correct, it should then follow that the crystals discovered nearest the extruding rhyolite mass will exhibit the greatest incidence of conversion of amethyst to citrine and green quartz. In keeping with this hypothesis, we observed that the amethyst crystals found farthest from the zone of metamorphism were a deeper purple than those found closest to the contact zone (see figure 2). Similarly, the greatest concentration of green quartz was unearthed nearest the rhyolite. Interestingly, we found little correlation between intensity of color and proximity to the rhyolite extrusion for the citrine. No variation in the transparency or flawlessness of any crystals was noted with location.

\section{COLORATION}

It is the iron impurity in silica that causes the purplish color of amethyst. According to Nassau (1980), "the iron merely provides the defect which permits the special amethyst color to occur." This purple coloration is due to a hole color center in amethyst. The iron impurity substitution in the silica structure is required for the hole center to occur. The hole-type color center forms where an absent electron causes the color. Thus, the word hole describes this electron absence.

Simply stated, the iron impurity in quartz causes amethyst color after the material is exposed to radiation. Heat destabilizes the color center and consequently produces citrine when ferric iron $\left(\mathrm{Fe}^{3+}\right)$ is present or green quartz when there is ferrous iron $\left(\mathrm{Fe}^{2+}\right)$, as explained in Nassau (1980). It is possible that the rhyolite extrusion provided the heat to produce these color alterations.

\section{GEMOLOGY OF THE GREEN QUARTZ}

The author examined approximately 45 specimens of amethyst, citrine, and green quartz. They 


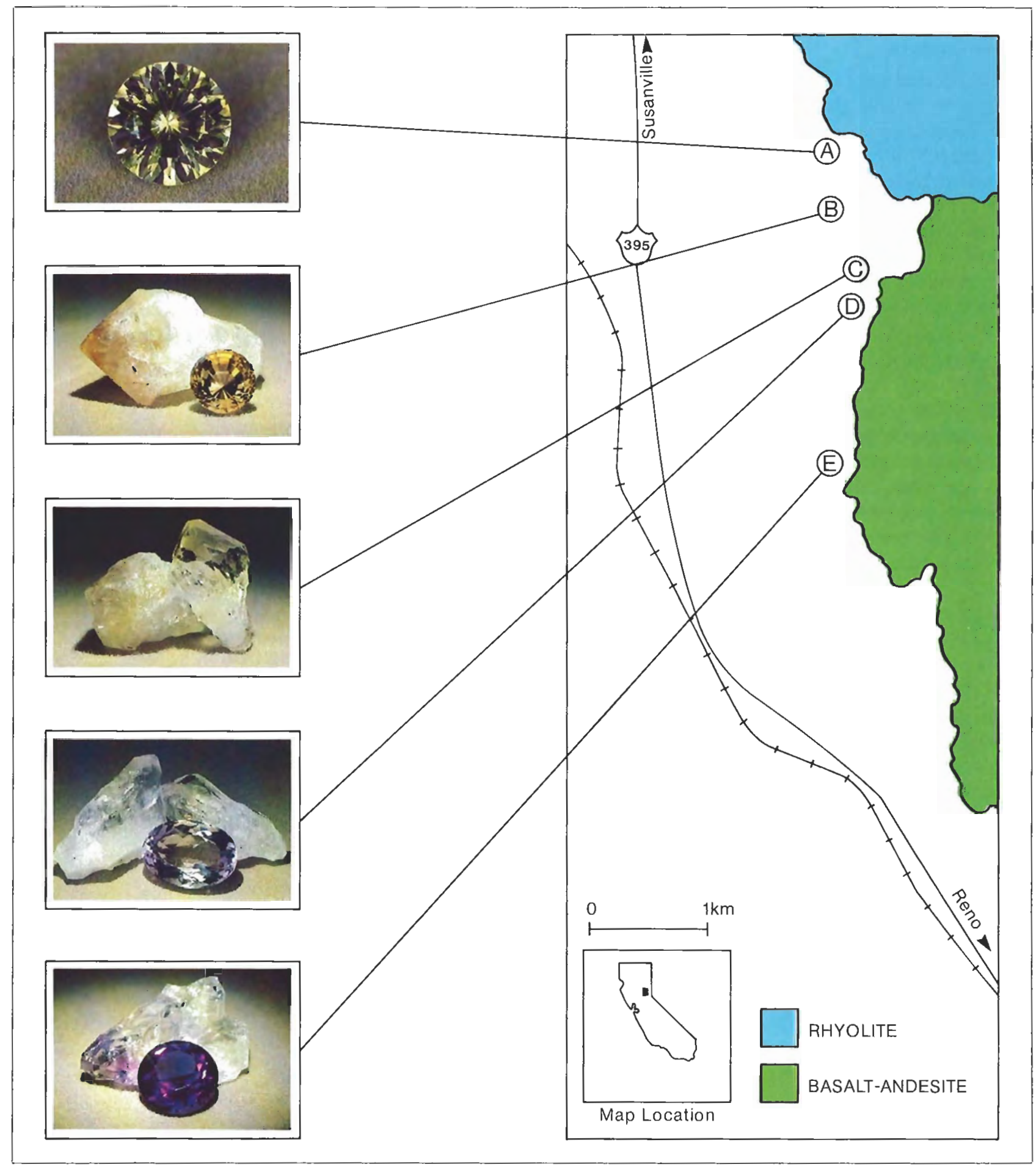

Figure 2. This map and the accompanying photographs illustrate representative discovery sites for the green quartz, citrine, light amethyst, and dark amethyst in relation to the host basalt and extruding rhyolite. The distribution of the discovery sites lends support to the hypothesis that the alteration in color of the amelhyst to green quartz is directly related to the heat provided by the rhyolite extrusion. $A=$ faceted green quartz, $4.99 \mathrm{cts}$; $B=$ faceted citrine $(5.74 \mathrm{cts}$.) with rough; $C=$ light green quartz rough (note that the green color is enhanced with faceting); $D=$ faceted light amethyst (19.30 cts.) with rough; $E$ = faceted dark amethyst $(3.77 \mathrm{cts}$.) with rough. Photographs by Tino Hammid, GIA Gem Media. Map drawn by Susan Kingsbury, GIA Gem Media. 
all exhibited the characteristic properties of quart $z$, with the green variety showing a weak iron spectrum absorption band centered at approximately $4420 \AA$, while both the citrine and amethyst from the same locale displayed considerably weaker (if any) iron absorption bands in the spectroscope. Slight color zoning and banding were observed in all the quartz specimens examined from this locality, with the ame thyst showing the greatest zoning and the green quartz the least.

The rough material found yielded one faceted round-brilliant-cut amethyst of deep color weighing $3.77 \mathrm{cts}$, one round step-cut citrine of medium color weighing 5.74 cts., one round-brilliant-cut green quartz weighing $4.99 \mathrm{cts}$, and two oval-faceted light amethysts weighing 19.30 and $2.05 \mathrm{cts}$. each (all but the last are in figure 2). These stones were exceptionally large in comparison to the majority of the rough material, with the remaining material capable of yielding singlecarat gems each for the most part. Again, the crystals were difficult to find; although some were found on the surface, others lay about two meters below. Many of the crystal clusters and fragments collected were heavily iron stained la brownish translucent coating); they were subsequently treated in a warm oxalic acid bath to remove the film and divulge the actual color and clarity of the specimen.

\section{CONCLUSION}

Iron-enriched silica developed and crystallized in existing vesicles and vugs in a basalt-andesite body along the Nevada-California border. Lowgrade radiation over a geologic period forced a hole color center to develop in the quartz and thereby gave it the purple color. We may then speculate that the secondary rhyolite extrusion and its tremendous accompanying heat caused the destabilization of the amethyst color and the subsequent development of the citrine and greenquartz coloration.

\section{REFERENCES}

Bateman P.C., Wahrhaftig C. $\{1960\}$ Geology of the Sierra Nevada. In Geology of Northern California, Bulletin I90, California Division of Mines and Geology, San Francisco, CA. Hill M. (I975) Geology of the Sierra Nevada. University of California Press.

Nassau K. (1980) Genns Made by Man. Chilton Book Co., Radnor, PA.

Sinkankas I. (1959) Gemstones of North America. Van Nosstrand Reinhold Co., New York.

Stinson M.C. (1960) Reconnaissance Geologic Maps of the Chilcoot, Sierraville, Portola and Loyalton Quadrangle. California Division of Mines and Geology, San Francisco, CA.

Webster R. (1978) Gems: Their Sources, Descriptions and Identification, 3rd ed. Camelot Press, Southampton, England. 